\title{
Long-Term Potentiation Disrupts Auditory Gating in the Rat Hippocampus
}

\author{
Christine L. Miller, ${ }^{1,2}$ Paula C. Bickford, ${ }^{1,3}$ Anne K. Wiser, ${ }^{2}$ and Gregory M. Rose ${ }^{1,2,3}$ \\ 'Department of Pharmacology and ${ }^{2}$ Neuroscience Training Program, University of Colorado Health Sciences \\ Center, and ${ }^{3}$ Veterans Affairs Medical Center, Denver, Colorado 80262
}

\begin{abstract}
The consequence of long-term potentiation (LTP) of hippocampal commissural inputs was investigated in an auditory gating paradigm. Auditory evoked potentials (AEPs) were recorded in the $\mathrm{CA}_{\mathrm{b}}$ region of the hippocampus of rats anesthetized with chloral hydrate. Two tones were deIlvered 0.5 sec apart; In thls paradigm, the second AEP is diminished compared to the first. Electrical stimulation was applied to hippocampal commissural fibers to generate field potentials and population spikes which were recorded at the same site as the AEPs. LTP of the commissural input (initiated by three trains of $250 \mathrm{~Hz} / 1$ sec stimulation) was associated with changes in the AEPs: on average, the response to the first tone decreased and the response to the second tone increased, resulting in the disruption of auditory gating. When high-frequency stimulation of the commissural input failed to result in LTP, no effect on the AEPs was seen. If 3-(2-carboxypiperazin-4-yl)-propyl-t-phosphonic acid (CPP; $6 \mathrm{mg} / \mathrm{kg}$, i.p.), an antagonist to the NMDA subclass of glutamate receptors, was administered prior to high-frequency stimulation, LTP induction was blocked and AEPs were not affected. Finally, reversal of LTP, achieved by high-frequency stimulation of CA3 input that was heterosynaptic to the particular commissural fibers at which the LTP was originally generated, caused disrupted auditory gating to return to normal. A model of reciprocal LTP and heterosynaptic depression of commissural and auditory input pathways is proposed to explain these findings.
\end{abstract}

[Key words: long-term potentiation (LTP), plasticity, hippocampus, CA3, auditory processing, sensory gating, rat, auditory evoked potentials]

The role of the hippocampus in the information processing required for learning and memory has been extensively studied. It is known that the hippocampus serves as a multi-modal association cortex, bringing together diverse sensory input (Swanson, 1983). Hippocampal neurons are responsive to complex spatial cues, a charactcristic which is consistent with a role for the hippocampus in spatial learning (O'Keefe and Nadel, 1978; Kubie and Ranck, 1983; McNaughton et al., 1983). At the cellular level, hippocampal long-term potentiation (LTP) has been

Received Dec. 28, 1994; revised Apr. 5, 1995; accepted Apr. 11, 1995.

This work was supported by the VA Medical Research Service and USPHS Grants MH-38321 and MH-44212. C.L.M. was supported by NIH Grant 1 T32 HD07408-01A1 and a grant from the Stanley Foundation.

Correspondence should be addressed to Dr. G. M. Rose, Medical Research Service (151), VAMC, 1055 Clermont Street, Denver, CO 80220.

Copyright (C) 1995 Society for Neuroscience 0270-6474/95/155820-11\$05.00/0 implicated as a mechanism underlying learning and memory (Swanson et al., 1982; Teyler and Discenna, 1984; Morris, 1990). Alternatively, the information processing that precedes memory encoding may require LTP (DeJonge and Racine, 1985; Squire, 1987).

Auditory information is part of the sensory spectrum that the hippocampus acts upon (Berger et al., 1976; Rose, 1983; Brankack ct al., 1986; Bickford-Wimer ct al., 1990; Edcline ct al., 1990). This information relayed to the hippocampus from several brain regions, including the medial septum (Harrison et al., 1988; Miller and Freedman, 1993) and the auditory responsive region of the entorhinal cortex (Stafekhina and Vinogradova, 1975; Vayssettes-Courchay and Sessler, 1983; Foster et al., 1988).

In general, auditory processing can be divided into two categories: (1) that occurring in the classical lemniscal system, which primarily involves signal frequency, intensity, and timing discriminations (Kelly, 1991); and (2) that occurring in extralemniscal pathways, which exhibits plasticity to sounds of behavioral significance (Weinberger and Diamond, 1987; Weinberger et al., 1990). Hippocampal processing is extra-lemniscal (Jirsa et al., 1992). Thus, learning changes the response of hippocampal neurons to auditory stimuli which have acquired behavioral significance (Berger et al., 1976; Edeline et al., 1990). Since these changes must be the result of learning-related modifications in the selective weighting of inputs to the hippocampal neurons, changes in synaptic strength induced by artificial means (e.g., LTP stimulation) might also be expected to modify hippocampal processing of auditory stimuli.

The type of hippocampal auditory processing we have studied is shown in Figure 1, which illustrates a mid-latency (N40) evoked potential that can be recorded in the hippocampus of a rat $40 \pm 10 \mathrm{msec}$ after a $3 \mathrm{kHz}, 70 \mathrm{~dB}$ tone and which shows diminished amplitude if an identical tone is presented $500 \mathrm{msec}$ later. This phenomenon is termed auditory gating, and may rclatc to models of hippocampal function involving the filtering out of irrelevant stimuli (Douglas, 1972; Solomon, 1977). Auditory gating is reflective of processing in the central extra-lemniscal pathway and is not observed in nuclei of the central lemniscal pathway (Bickford-Wimer et al., 1990; Bickford et al., 1993).

How might LTP interact with auditory gating in the hippocampus? The impact of LTP has been difficult to determine in terms of a specific in vivo consequence to an animal (Eichenbaum and Otto, 1993). Yet, assuming that alterations in the strengths of synaptic input occur in vivo, such changes should affect hippocampal function in some manner. In this study, we investigated the effect of LTP on auditory gating of the N40 


\section{Conditioning Response}

Test

Response
T/C Ratio
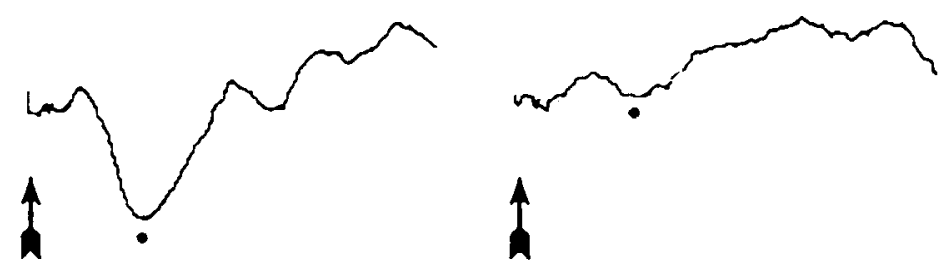

\subsection{Gating}
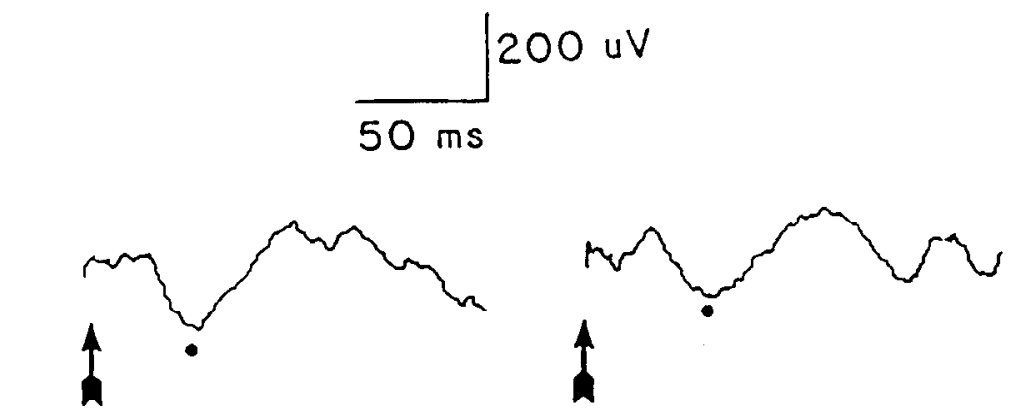

\subsection{Gating Lost}

\section{Ist tone}

\section{2nd tone}

Figure 1. Examples of $\mathrm{N} 40$ potentials (marked by dots) recorded in $\mathrm{CA} 3_{b}$, elicited by paired auditory stimuli that are separated by 500 msec (marked by arrows). The upper set of potentials is representative of baseline auditory gating. A $T / C$ ratio of 0.5 is considered to be the level above which gating is lost (see Materials and Methods). The lower set of potentials illustrates a loss of auditory gating resulting from a decrease in the conditioning response amplitude and an increase in the test response amplitude.

potential recorded in the hippocampus of the rat. In common with LTP, auditory gating is a process that is reflectcd in cxtracellular potentials and can be measured electrophysiologically at the site of LTP generation. The paradigm involves fewer dimensions than learning and memory studies and is more closely associated with the substrate upon which LTP acts: excitatory input to hippocampal pyramidal cells and interneurons.

\section{Materials and Methods}

Animals and surgery. Thirty-four adult male Sprague-Dawley rats (250-350 gm; Harlan Laboratories, Indianapolis, IN) were recorded during the course of this study. The animals were anesthetized with chloral hydrate $(400 \mathrm{mg} / \mathrm{kg}$, i.p.) which had been prepared in a buffered solution of $100 \mathrm{~mm} \mathrm{NaCl}$ and $50 \mathrm{~mm}$ HEPES (final $\mathrm{pH} \mathrm{7.2)} \mathrm{and} \mathrm{stored} \mathrm{at}$ $4^{\circ} \mathrm{C}$ until use. Chloral hydrate was selected as the anesthetic because it preserved the auditory response very well, whereas other anesthetics tried (pentobarbital and urethane) did not. To extend the period of stable anesthesia, the metabolism of chloral hydrate to trichloroacetic acid was blocked by the administration of pyrazole, an inhibitor of alcohol dehydrogenase (Cooper and Friedman, 1958; Miller et al., 1993). Pyrazole was injected intraperitoneally at a loading dose of $200 \mathrm{mg} / \mathrm{kg}$, with 30 $\mathrm{mg} / \mathrm{kg}$ supplements at $30 \mathrm{~min}$ intervals.

The level of anesthesia was carefully monitored throughout the course of the experiment, and was adjusted with supplemental doses of chloral hydrate as necessary. The anesthesia level was judged to be inadequate when there was response to toe pinch and/or presence of the corneal reflex to touch with dry cotton wisp. A state of excessive anesthesia was determined to exist when the corneal reflex was no longer present to the application of a wet cotton wisp. Based on observations from previous work (Miller et al., 1992, 1993), and also observed here, conditions of either too much or too little anesthesia resulted in variable changes in the size of hippocampal field potentials and auditory N40, and consistently disrupted auditory gating. However, when a stable and appropriate level of anesthesia was maintained these problems were not observed (Miller et al., 1993; see Results).
Electrophysiology. The rats were secured in a stereotaxic apparatus, adjustments were made to ensure that the skull was flat, and after removal of small sections of the skull and dura, a recording electrode (tungsten, coated with non-conducting varnish; 3 to $5 \mathrm{M} \Omega$ resistance) was lowered into the hippocampus (from bregma, $-3.8 \mathrm{~mm} \mathrm{AP}, 3.6$ $\mathrm{mm} \mathrm{ML}$ ). A stimulating electrode (tungsten, coated with nonconducting varnish; $0.25 \mathrm{M} \Omega$ resistance) was lowered to one of three different stercotaxic locations to stimulate commissural input to the recording electrode site: (1) in the ventral hippocampal commissure $(-1.8 \mathrm{~mm}$ AP, $1.0 \mathrm{~mm} \mathrm{ML}$, and 2.7-2.9 mm DV; see Swanson, 1992), (2) in the contralateral CA3 anterior to the plane of the recording electrode $(-1.8$ $\mathrm{mm} \mathrm{AP}, 1.0 \mathrm{~mm} \mathrm{ML}$, and $3.4-3.5 \mathrm{~mm} \mathrm{DV}$ ), or (3) in the contralateral CA3 homotopic to the recording electrode site $(-3.8 \mathrm{~mm} \mathrm{AP,} 3.7 \mathrm{~mm}$ $\mathrm{ML}$, and 2.9-3.4 mm DV). Stereotaxic locations of recorded groups of cells was used as an aid to correct placement of the recording electrode. The initial landmarks used were the field potential induced by commissural stimulation and the presence of neurons firing with the complex spike characteristic of hippocampal pyramidal cells, first encountered at the depth corresponding to the CA1 layer (usually $1.9-2.2 \mathrm{~mm}$ from the dura). Extracellular recordings of action potentials were amplified by a high-input impedance amplifier and then further amplified and displayed on the oscilloscopc. For the action potential recordings, the bandpass filter was set to limit the response to $300-10,000 \mathrm{~Hz}$. Below the CA1 pyramidal layer, the potentials evoked by stimulation of the commissure were characteristic dendritic negativities until the CA3 pyramidal layer was reached at depths generally $>2.9 \mathrm{~mm}$. Complex spikes of $\mathrm{CA} 3$ pyramidal cells were always recorded, but more diagnostic was the distinctive antidromic response to commissural stimulation found in CA3 but not in CA1 (Fig. 2). The electrode was determined to be in the pyramidal cell layer of $\mathrm{CA}_{b}$ and not $\mathrm{CA} 3_{c}$ or $\mathrm{CA}_{\mathrm{a}}$, if, while lowering the electrode, (1) the dentate gyrus granule cell layer was not encountered, and (2) pyramidal cells were recorded in a discrete band and not in a more continuous dorsal/ventral band corresponding to $\mathrm{CA} 2 / \mathrm{CA} 3_{\text {a }}$.

Sufficient negative (cathodal) current of $150 \mu \mathrm{sec}$ pulse width was administercd to the stimulating clectrode to generate a $\mathrm{CA} 3$ population spike and/or a field potential, each of at least $1 \mathrm{mV}$ amplitude. The 
A.

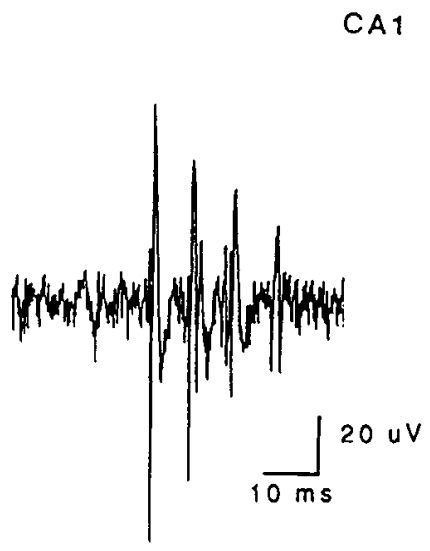

B.

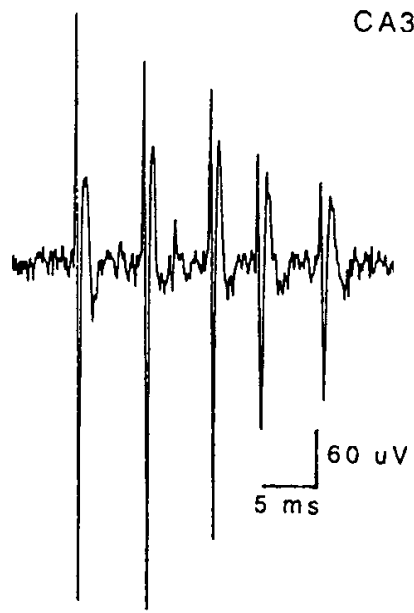

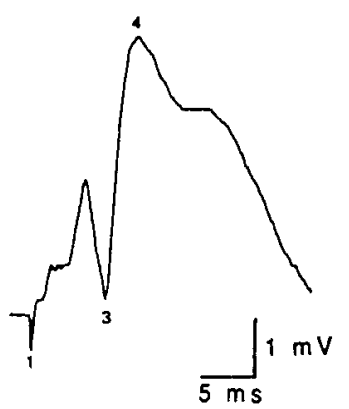

Anterior CA3

Homotopic CA3

Stimulator

placement

$\mathrm{VHC}^{b}$

Anterior $\mathrm{CA} 3$

CA3

" LTP of the population spike.

${ }^{b}$ Ventral hippocampal commissure.

(see Results). This approach was successful in three of three rats, which were then included in the +LTP data set.

Once the post-LTP response had stabilized, the variability of the population spike amplitudes, averaged over $5 \mathrm{~min}$ intervals of time (similar to the time period of the baseline collection), ranged from $3 \%$ to $32 \%$, or 0.6-3-fold the variability seen in the pre-LTP period (paired, withinanimal observations). The variability in the field potential amplitudes ranged from $2 \%$ to $18 \%$, or $0.6-2.2$-fold the variability seen in the preLTP period.

The auditory evoked potentials were elicited by presentation of tones $(3000 \mathrm{~Hz}, 70 \mathrm{~dB}$ SPL, $10 \mathrm{msec}$ duration) through hollow stereotaxic earbars. The auditory stimulus intensity was selected to fall in the middle of a plateau. At intensities above approximately $50 \mathrm{~dB}$ the amplitude of the evoked potential shows no significant change with intensity level (unpublished data), and below $90 \mathrm{~dB}$ the startle mechanism is not a confounding factor (Keith et al., 1991).

Two tones, separated by $500 \mathrm{msec}$, were presented every $10 \mathrm{sec}$. Signals were filtered such that only electrical activity with frequencies between 0.1 and $1000 \mathrm{~Hz}$ were recorded. Sixteen pairs of tones were presented in each trial and an average waveform was constructed from the digitized components of the $16 \mathrm{~N} 40$ responses. Test/conditioning $(T /$ $C$ ) ratios were calculated from the average waveform. The mean $T / C$ ratio for a specific period of analysis represents the mean of all the $T /$ $C$ ratios calculated for each trial during that period. Historically, a $T / C$ ratio of $>0.5$ has been associated with psychosis in humans (Adler et al., 1982; Freedman et al., 1987). Similar $T / C$ ratios are seen following the administration of drugs at doses that are known to have psychotomimetic effects in rats (Adler et al., 1986; Miller et al., 1992). A $T / C$ ratio of 0.5 is $>2$ SD units above the mean value of $0.25-0.35$ found for controls in previous studies (Miller et al., 1992, 1993) and is considered to be the value above which gating is lost. The minimum time separating trials of auditory evoked potentials was 5 min. A minimum of four trials was collected prior to high-frequency electrical stimulation to confirm that a given animal's auditory gating was stable. Any rat which failed to show consistent auditory gating was excluded from further study. Viral infections or, as was explained earlier, cyanosis from too much anesthesia can lead to lack of gating in our paradigm. In addition, approximately $10 \%$ of the rat subjects fail to gate the $\mathrm{N} 40$ for

\begin{tabular}{|c|c|c|}
\hline $\begin{array}{l}\text { Stimulator } \\
\text { placement }\end{array}$ & $\begin{array}{l}\text { LTP of population } \\
\text { spike }{ }^{a} \\
(\text { mean } \% \\
\text { control } \pm \mathrm{SD})\end{array}$ & $\begin{array}{l}\text { LTP of field } \\
\text { potential } \\
\text { (mean \% } \\
\text { control } \pm \text { SD) }\end{array}$ \\
\hline VHC & $210 \pm 170$ & $228 \pm 92^{*}$ \\
\hline Anterior CA3 & $327 \pm 232$ & $168 \pm 68$ \\
\hline Homotopic CA3 & $264 \pm 138$ & $118 \pm 16$ \\
\hline
\end{tabular}

"Values do not include those experiments in which no prior population spike was recorded

*Value is significantly different from the others in this column, $p<0.03$. 
unknown reasons; those rats were excluded as well. Following highfrequency electrical stimulation, trials of auditory evoked potentials and electrically evoked potentials were conducted. The minimum time interval separating a trial of auditory evoked potentials from a trial of electrically evoked potentials was $1 \mathrm{~min}$, and the maximum interval was usually $<10 \mathrm{~min}$.

Statistics. Data are expressed as mean \pm the standard deviation, unless otherwise specified. Significant differences between values obtained in an individual rat, before and after treatment, were determined using an unpaired, two-tailed, $t$ test comparing all the values before treatment to all the values after treatment $(n>4$ in all cases for $T / C$ ratio; $n>$ 6 in all cases for electrically evoked potentials). Significance was set at $p<0.05$. Thus, a statement that no potentiation was observed in four rats indicates that in no case was there a significant difference in the before and after values in those four rats. In cases of successive treatInents in the same rat, the significance of a treatment was always cstablished as compared to the baseline (control) condition for that particular rat. In no case was a statistical test applied to determine if the $T / C$ ratio was significantly different than the value of 0.50 , above which gating is considered to be lost.

The data were analyzed for a specified group of rats by computing mean values for the before and after treatment conditions, pairing those values for each rat, and then applying a paired, two-tailed $t$ test to assess the significance level of the data across the group. Thus, for all cases in which data is cited for a group of rats, the $t$ test that was applied was paired. Significance was set at $p<0.05$.

\section{Results}

\section{Electrical and auditory stimulation}

The auditory and electrically evoked potentials were recorded in $\mathrm{CA} 3_{b}$, a region which lies ventral and lateral to the buried blade of the dentate gyrus, but medial to the flexure of CA3. $\mathrm{CA} 3_{b}$ receives virtually all of its commissural input from the contralateral $\mathrm{CA} 3_{\mathrm{b}}$ (Voneida et al., 1981), and thus, is relatively free of the potentially confounding influence of dentate efferents (Steward et al., 1990) that project across the ventral hippocampal commissure to other regions of the hippocampus (Voneida et al., 1981). Previous work had revealed a population of auditory responsive pyramidal cells in the $\mathrm{CA} 3_{\mathrm{b}}$ region, as well as robust N40 auditory evoked potentials (Bickford-Wimer et al., 1990).

Three different stimulator placements were uscd: (1) in the ventral hippocampal commissure, (2) in the contralateral CA3 anterior to the recording electrode, and (3) in the contralateral CA3 homotopic to the recording electrode site. Stimulus-evoked potentials recorded in response to the three stimulator placements were similar in form, although there were some differences in stimulus thresholds (Table 1). LTP of the field potential and/or population spike was achieved in 28 of 31 rals studied. In four rats, the peak amplitude of the positive field potential was increased without a corresponding potentiation of the population spike, and on two occasions the population spike increased without a corresponding potentiation of the positive field potential. Stimulator placement had an influence on whether the positive field potential or the population spike was more affected by high-frequency stimulation. The positive field potential was potentiated to the greatest degree following stimulation of the ventral hippocampal commissural fiber tract placement (one-way ANOVA, $p<0.03$; Table 2). The population spike showed a trend to he potentiated to the greatest degree by stimulation of the anterior CA3 placement, but this trend did not reach statistical significance. There was no correlation between the magnitude of population spike increase and the positive field potential increase $(r=0.03, p>0.8)$, a finding replicating previous work that showed a correlation between potentiation of the population spike and the negative-going dendritic field potential but no correlation with the positive field potential recorded at the cell soma (Rose et al., 1993).
Auditory-evoked potentials to paired tones were recorded at the same site and through the same electrode as the electrically evoked potentials, although not at the same time. The ratio of the test response to the conditioning response ( $T / C$ ratio) was calculated for each of four trials and stable auditory gating was confirmed prior to administering a high-frequency train of stimuli through the stimulating electrode (Fig. 1). There was a weak positive correlation between the conditioning and test amplitudes under baseline conditions $(r=0.46, p<0.001)$. For the 31 rats studied in this series of experiments, the mean baseline $T / C$ ratio was $0.28 \pm 0.08$.

\section{The effect of LTP on auditory gating}

The development of LTP significantly disrupted auditory gating (Fig. 3). The field potential and population spike were monitored for $5 \mathrm{~min}$ and then auditory evoked potentials and electrically evoked potentials were alternately collected for at least $1 \mathrm{hr}$ following the high-frequency electrical stimulation of contralateral/commissural input to $\mathrm{CA} 3$. In the 28 rats showing LTP (i.e., potcntiation for periods $>1 \mathrm{hr}$; see Materials and Methods), the mean change over a $1 \mathrm{hr}$ LTP period was $+275 \pm 192 \%$ in the population spike $(p<0.0001),+177 \%$ ( $80 \%$ in the field potential amplitude $(p<0.0001)$ and $+0.48 \pm 0.40$ in the $T / C$ ratio $(p<0.0001)$. In contrast, potentiation that was not stable (see Materials and Methods) did not result in disruption of auditory gating (as shown for the $T / C$ ratio and population spike in Fig, 4). Within individual rats the variability of the $T / C$ ratio between trials went up, on average, fourfold during LTP. This large post-LTP increase in variability of $T / C$ ratio derived from an increase in variability of both the conditioning (1.4-fold) and the test (1.9-fold) amplitudes, as well as an increase in variability of the relationship between the conditioning and test amplitudes.

Although the mean $T / C$ ratio over four consecutive trials remained perturbed for the duration of the LTP, the auditory gating frequently showed intermittent normalization in single trials (Fig. 4), when the $T / C$ ratios fell to $<0.50$. Intermittent normalization has also been observed in experiments investigating the pharmacological perturbation of auditory gating (Miller et al., 1992) and in part may result from shifts in the populations of neurons responding to the tone (Miller and Freedman, in press). However, this normalization was never observed for more than two consecutive trials, which distinguished the LTP period from the pre-LTP period. The increased variability discussed above, and illustrated in Figure 4, could be interpreted as simply an increase in noise in the system following LTP induction; however, the intermittent periods of normalization after LTP were always bracketed by extended periods of gating disruption. It does not seem likely that the increase in mean $T / C$ ratio which occurred during LTP resulted from the interaction of the variability with a floor effect because the lowest $T / C$ ratio during LTP was still higher than the lowest $T / C$ ratio encountered in each rat during baseline conditions (in all cases, including that presented in Fig. 4).

The aspect of LTP that correlated with the loss of gating of the N40 was the magnitude of the population spike increase ( $r$ $=0.6, p<0.0007)$. In contrast, there was no correlation between gating loss and enhancement of the positive field potential potentiation $(r=0.17 ; p>0.3)$. There was a positive correlation between the LTP-induccd incrcasc of population spike and the increase in $T / C$ ratio (indicating a reduction of gating) for all three stimulator placements, although a significant relationship between the two variables was found only for LTP induced by 
A.

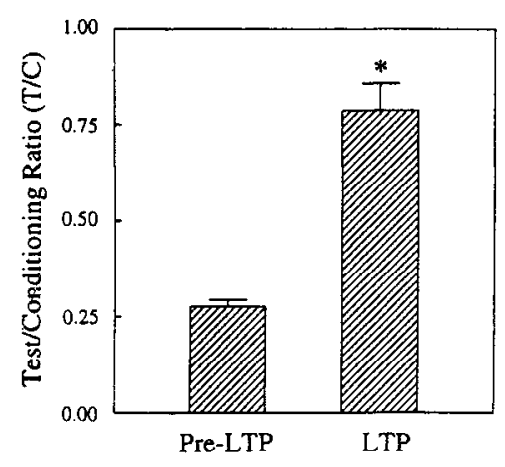

B.

Field Potentials and Population Spikes

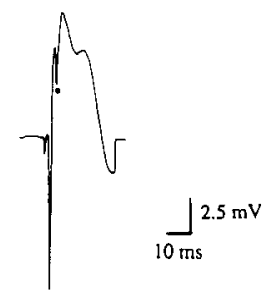

BASELINE

N40 Evoked Potentials

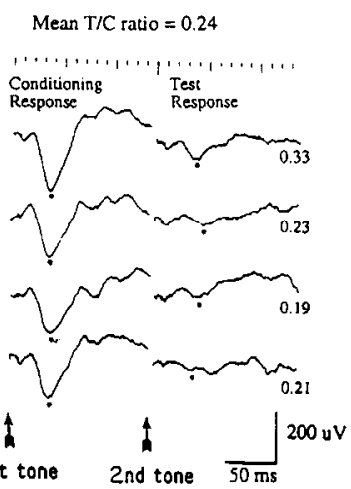

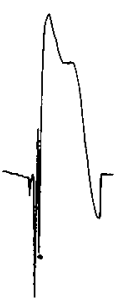

$+\mathrm{LTP}$ vealed that the gating loss was statistically significant $(n=28 ; p<$ $0.0001)$. The $T / C$ ratios are graphed as means \pm SEM. $B$, An representative experiment. Top, LTP was induced by stimulation of the VHC. Bottom, Four consecutive samples of auditory evoked potentials recorded prior to LTP stimulation (left) and during LTP (right). These data illustrate the transition from test amplitude increase to conditioning amplitude depression which followed successful LTP induction. The elapsed time from the first BASELINE N40 evoked potentials shown to the last was $30 \mathrm{~min}$. The elapsed time from the first + LTP N40 evoked potentials shown to the last was $15 \mathrm{~min}$.

tetani delivered through the contralaterally placed stimulators (Fig. 5).

In no case did LTP stimulation have an immediate effect on auditory gating. This finding was independent of stimulator placement. From the time of the peak potentiation observed within the first $10 \mathrm{~min}$ following the high-frequency train, the mean time to onset of the auditory gating loss was $10.5 \pm 7$ min (range, 4-29 min).

Following LTP, both the N40 conditioning amplitude and test amplitude were significantly altered compared to baseline values ( $p<0.05$; paired $t$ test): the conditioning amplitude decreased and the testing amplitude increased. Furthermore, the effect had two phases (Table 3). Initially, the auditory gating was disrupted primarily by a large increase in the test amplitude. These short term values for test amplitude were significantly greater than the test amplitude values at later time points $(p<0.01)$. It was generally the case that, within 5-15 min of the initial disruption of gating, the conditioning amplitude depression became more pronounced, although overall this change was not significantly different from the reduction in conditioning amplitude associated with the initial gating loss ( $p>0.05$ ). Figure $3 B$ illustrates such a transition in the conditioning and test amplitudes.

Controls for effects of high-frequency electrical stimulation not related to LTP of the population spike

In three rats, high-frequency electrical stimulation failed to potentiate either the field potential (mean change $=-30 \pm 44 \%$; $p>0.35$ ) or the population spike (mean change $-3.7 \pm 5.5 \%$; $p>0.36$ ). In these cases, the resulting mean change from baseline $T / C$ ratio was not significant $(-0.02 \pm 0.08, p>0.40$; Table 4 , group E). In four other rats, only the field potential was potentiated (mean change $=+83 \pm 6 \% ; p<0.001$; mean change in population spike $=-11 \pm 22 \% ; p>0.41$ ). For these animals also, no significant change from baseline $T / C$ ratio was observed after high-frequency electrical stimulation $(+0.07 \pm 0.09 ; p>$ 0.30; Table 4, group D).

As a further control for potential nonspecific effects of highfrequency electrical stimulation, three rats received and intraperitoneal dose of $6 \mathrm{mg} / \mathrm{kg}$ of the competitive NMDA antagonist CPP, 20 min prior to high-frequency stimulation of the ventral hippocampal commissure (two animals) or anterior CA3 (one animal). Commissural LTP is NMDA dependent (Collingridge et al., 1983; Zalutsky and Nicoll, 1990); therefore, it was possible to block LTP with the prior administration of CPP. In CPPtreated rats, as expected, LTP was not generated by the highfrequency electrical stimulation; in addition, auditory gating was not perturbed. The mean change was $-2.6 \pm 2.3 \%(p>0.15)$ in the population spike amplitude, $+10 \pm 37 \%(p>0.50)$ in the positive field potential amplitude and $-0.04 \pm 0.12(p>$ 0.6 ) in the $T / C$ ratio (Table 4 , group F). These data show that the auditory gating loss and the LTP are correlated in that they both require activation of the NMDA receptor in this paradigm. Thus, the CPP data serves as a control for aspects of high-frequency stimulation that are unrelated to activation of the NMDA receptor.

Is it a significant finding that rats which did not develop LTP of the population spike also did not experience a change in auditory gating? Dividing the 34 member experimental population (Table 4) into two groups, those that developed LTP of the population spike and those that did not, and applying one-way ANOVA to the change in $T / C$ ratio experienced by the two groups following high-frequency stimulation, the finding was determined to be significant $(F=17.4 ; p<0.0002)$. In contrast, the same analysis applied to LTP of the positive field potential revealed $\mathrm{no}$ relationship to changes in auditory gating $(F=0.62$; $p=0.44)$. 


\section{- Population Spike Amplitude}

\section{$\Delta \quad$ Test/Conditioning Ratio}

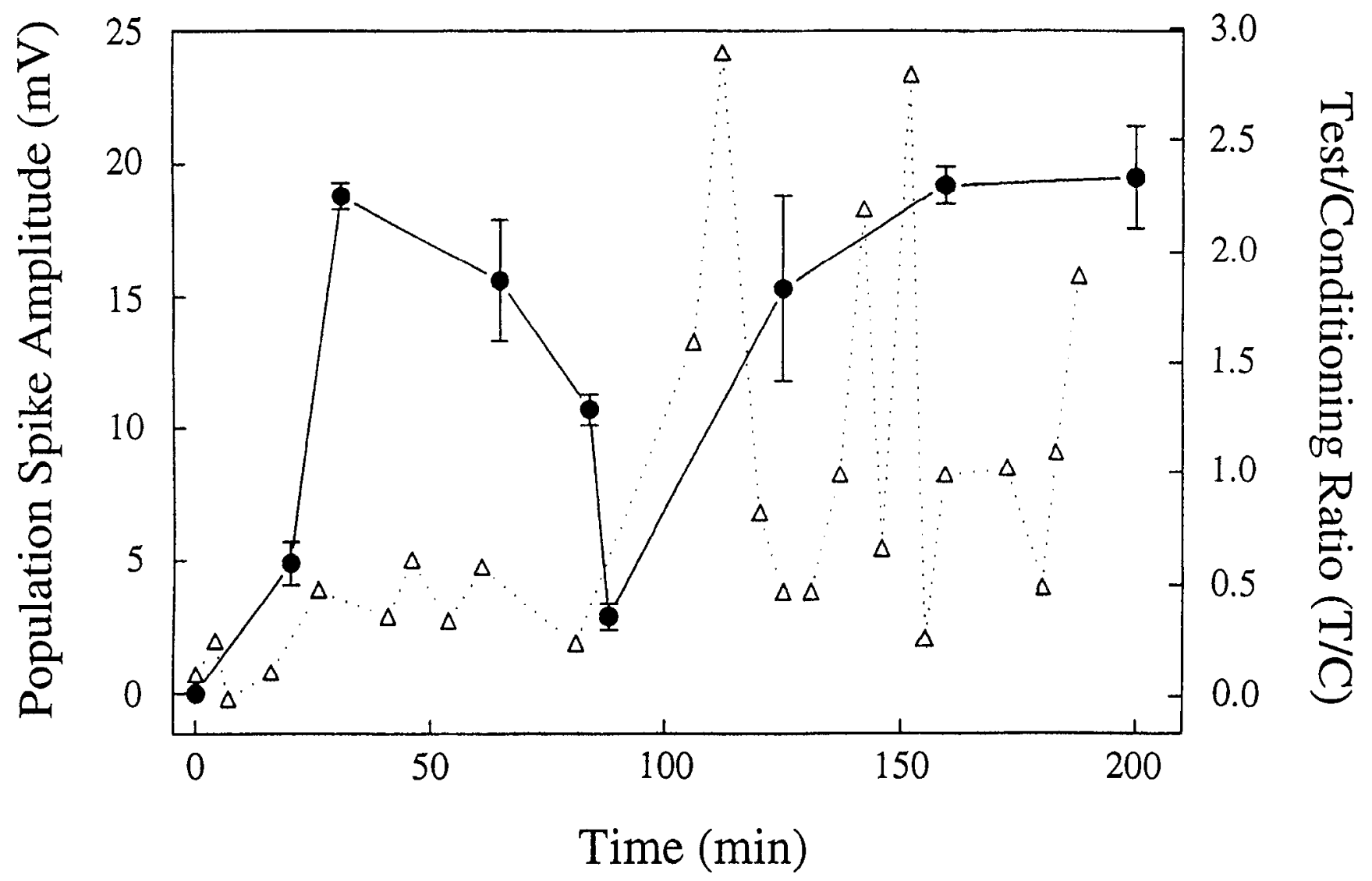

Figure 4. Time course of an experiment in which the first high-frequency train (delivered at the 20 min time point) elicited a potentiation that was not stable (see Materials and Methods). Disruption of auditory gating (mean $T / C$ ratio $>0.5$ ) occurred only with the development of LTP following the second train (delivered at the 95 min time point). The time course of the potentiation following the second high-frequency train is characteristic of the + LTP experiments. The mean $T / C$ ratios were $0.12 \pm 0.11$ for the baseline period, $0.44 \pm 0.15$ for the period following the first train, and $1.25 \pm 0.84$ for the period following the second train. This finding was replicated in two additional rats.

\section{A. VHC Stimulation}

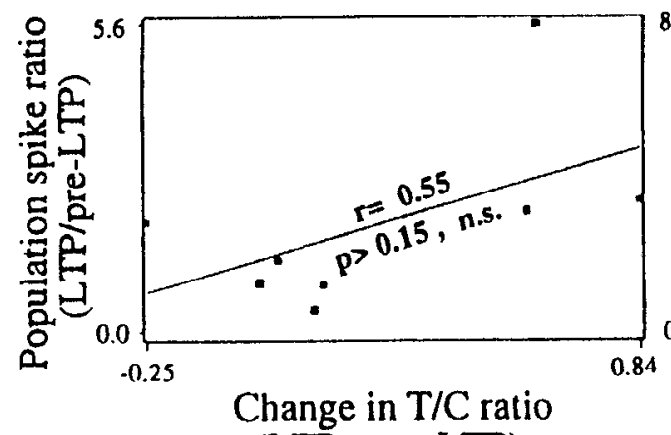

(LTP - pre-LTP)
Contralateral

B. Anterior CA3 Stimulation

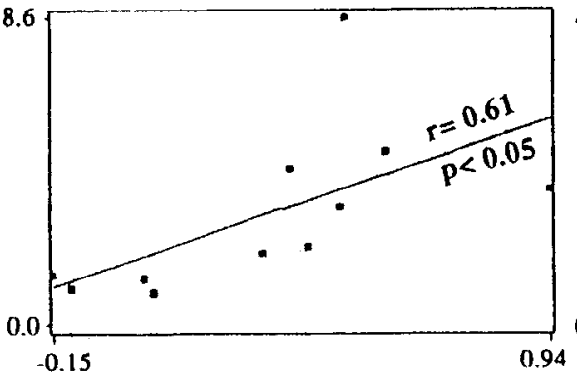

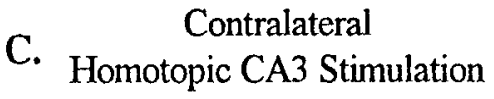

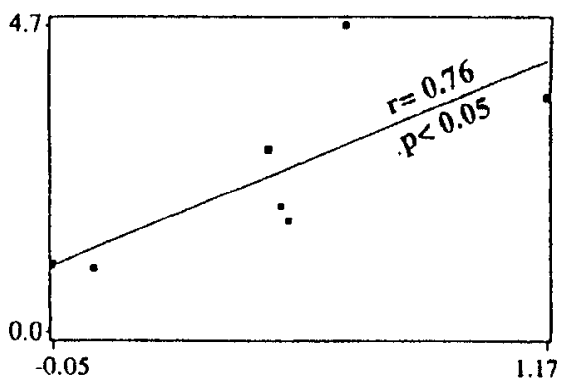

Figure 5. Correlation between LTP of the population spike and loss of auditory gating for three different stimulator placements. The data set does not include experiments in which there was no population spike prior to LTP. $A$, Stimulator location in the ventral hippocampal commissure. $B$, Stimulator location in the anterior CA3, contralateral to the recording electrode. $C$, Stimulator location in $C A 3_{b}$, contralateral and homotopic to the recording electrode. In all cases there was a positive correlation between LTP-induced growth of the population spike and an increased $T / C$ ratio, indicating a reduction in gating. However, these correlations were statistically significant only for the anterior CA3 and contralateral/homotopic stimulator placements. 
Table 3. The contribution of conditioning amplitude depression and test amplitude increase to the loss of auditory gating seen with LTP: initial and delayed effects

\begin{tabular}{lll}
$\begin{array}{l}\text { Elapsed } \\
\text { time } \\
(\text { min })^{a}\end{array}$ & $\begin{array}{l}\text { Mean change in } \\
\text { conditioning } \\
\text { amplitude } \\
(\% \text { control } \pm \mathrm{SD})\end{array}$ & $\begin{array}{l}\text { Mean change in } \\
\text { test amplitude } \\
(\% \text { control } \pm \text { SD })\end{array}$ \\
\hline 0 & $-25 \pm 30$ & $+107 \pm 57$ \\
$5-60^{s}$ & $-43 \pm 20$ & $+78 \pm 56^{*}$
\end{tabular}

"time since first onset of auditory gating loss. Zero minutes represents only one trial.

" The 5-60 min time point represents the mean, for each experiment, of all the trials for $60 \mathrm{~min}$ following the onset of the auditory gating loss, summed for all experiments in which there was LTP of the population spike $(N=21)$ to generate an overall mean.

* Significantly different from 0 time point, $p<0.01$.

\section{Reversal of LTP and normalization of auditory gating}

Placement of stimulating electrodes in the anterior CA3 and the homotopic CA3 revealed an apparent heterosynaptic depression if high-frequency stimulation was applied alternately to both sites of stimulation. Furthermore, if the second input yielded a poor population spike response while the first yielded a robust population spike response, it was possible to generate LTP at the first input and then reverse it by administering a high-frequency stimulus to the second input, without generating LTP of the second input. Thus, it was possible to use this heterosynaptic stimulation paradigm to first generate LTP, and then return to the baseline condition of no potentiated inputs.

Two stimulating electrodes were lowered, one to the contralateral anterior $\mathrm{CA} 3$ and the other to the contralateral $\mathrm{C} \wedge 3$ homotopic to the recording electrode. The stimulation site yielding the more sensitive population spike response for a given current intensity was selected as the site for initial LTP generation. Following LTP induction, reversal of the LTP was attempted by applying a high-frequency train $(250 \mathrm{~Hz}$, up to 400 $\mu \mathrm{A}, 150 \mu \mathrm{sec}$ pulse duration, for $1 \mathrm{sec}$ ) to the other commissural stimulator. Complete reversal of LTP was achieved in five of seven rats for varying amounts of time. In one of the failures, reversal of the original LTP occurred but LTP developed from the second site of high-frequency stimulation, and in the other, no reversal of LTP took place. In the successful reversal experiments, auditory gating was normalized to a mean $T / C<0.5$ (as defined in Materials and Methods) for the period during which the population spike amplitude was less than or equal to the original baseline value (Fig. 6). The mean time period of successful reversal of LTP was $24 \pm 8 \mathrm{~min}$ (range, 15-35 min), which covered at least four trials of auditory gating. In individual rats, the $T / C$ ratios during reversal were compared to an equivalent number of trials during LTP. The minimum mean $T /$ $C$ ratio during LTP was significantly greater than the mean $T / C$ ratio during reversal in all five animals $(p<0.05)$. Furthermore, there was no significant difference between the $T / C$ values during reversal and the original baseline $T / C$ values (mean difference, $0.02 \pm 0.10$; range, -0.10 to $+0.14 ; p>1.0$ ). Within individual rats, the variability in the $T / C$ ratio decreased from approximately fourfold during LTP to an average of 1.3 times that of the baseline during the reversal period.

Comparison of the mean difference between the electrically evoked positive field potentials during reversal and the original baseline values revealed no significant difference (mean, -11.7 $\pm 16.6 \%$; range, $-29 \%$ to $+10 \%$ ). Comparisons for individual rats indicated no significant change in four rats $(p>0.3)$ and significant reduction in one $(p<0.005)$. Mean population spike amplitudes during reversal were $-22 \pm 37 \%$ (range, $-58 \%$ to $+33 \%$ ) compared to pre-LTP baseline values. Individual comparisons revealed no significant difference for two rats $(p>$ $0.25)$ and a significant reduction in the other three $(p<0.05)$.

\section{Discussion}

LTP of commissural input to the hippocampus disrupted auditory gating in a proportional and reversible manner. This effect is unlikely to have resulted from an aspect of high-frequency stimulation unrelated to LTP because (1) when high-frequency stimulation failed to generate LTP, gating was not altered; (2) when LTP was purposely prevented by the administration of an

Table 4. Summary of treatment and results

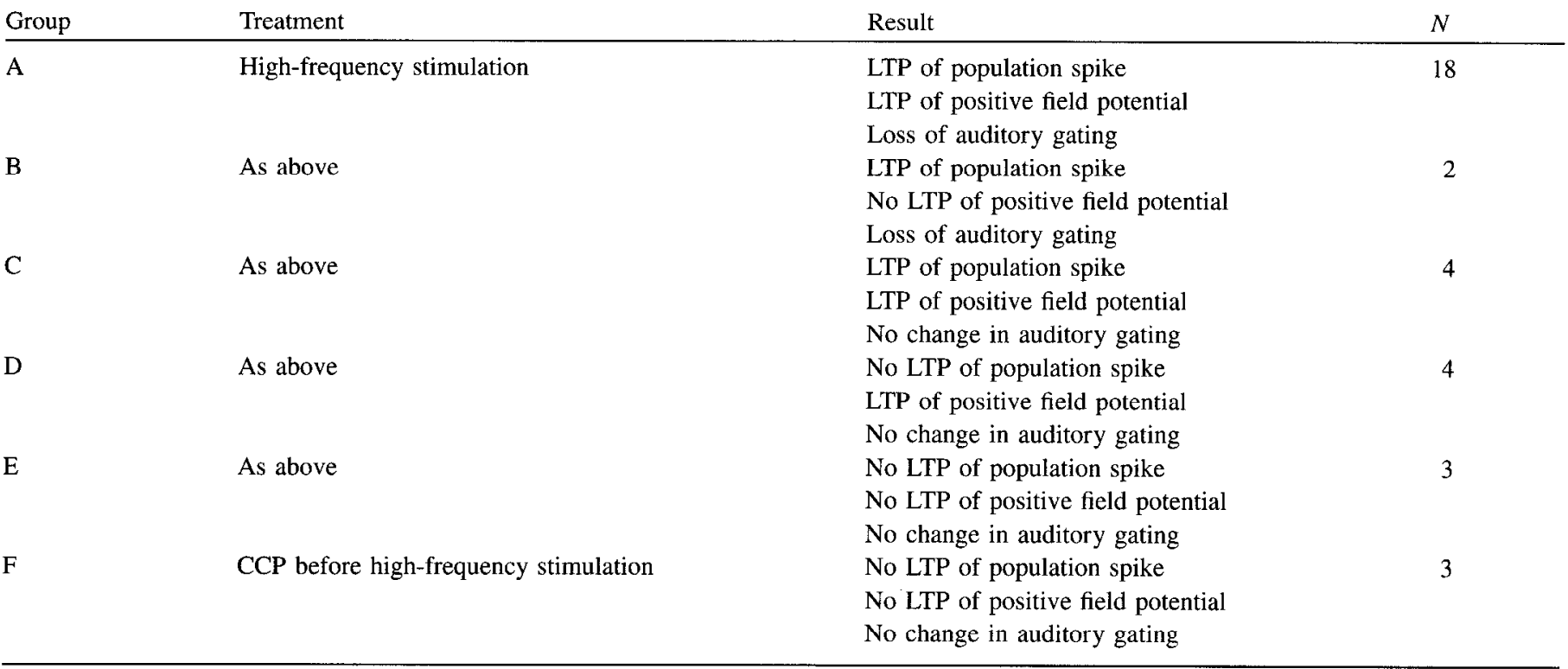




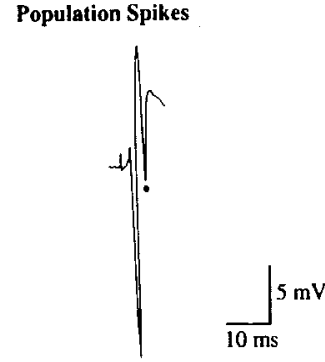

BASELINE
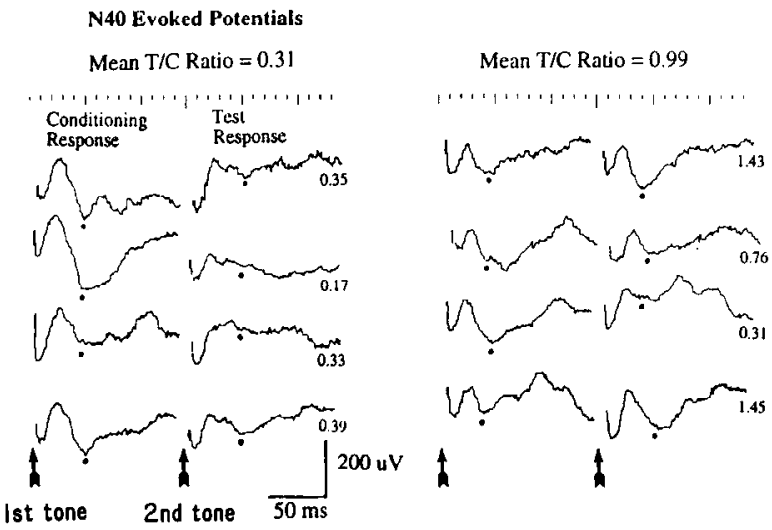

NMDA antagonist, gating was unchanged following high-frequency stimulation; and (3) high-frequency stimulation itself was used to normalize gating that had previously been perturbed by LTP.

Gating loss was correlated with an LTP-induced increase in the population spike, but not the positive field potential, recorded in the CA3 pyramidal cell layer. Population spikes are summed action potentials of pyramidal cells (Andersen et al., 1971) and therefore, are a reflection of postsynaptic excitation. Extracellular field potentials are thought to reflect excitatory and inhibitory synaptic currents generated at postsynaptic sites on pyramidal cells (Schlag, 1973; Leung, 1979; Di et al., 1990). Electrical stimulation of the commissure activates both excitatory and inhibitory synaptic currents within a few milliseconds of each other (Buzsaki and Eidelbery, 1982); the resulting the positive and negative currents sum, tending to cancel each other out. Due to this interaction between positive and negative currents, the peak magnitude of the extracellularly recorded positive field potential is not likely to reflect changes in excitatory input to pyramidal cells in a graded manner. In contrast, the population spike should provide more of a graded reflection of excitatory input to the pyramidal cells because the faster frequency action potential currents are not affected by the slower frequency field potential currents. This suggests that changes in synaptic strength will be more accurately represented by alterations in the population spike rather that in a field potential which is recorded distant from the site of synaptic input.

Theoretically, LTP of the excitatory synapses carrying the tone input should cause the $\mathrm{N} 40$ conditioning amplitude to increase in size. Rogan et al. (1993) have demonstrated such a relationship between tone evoked potentials and LTP of medial geniculate afferents to the amygdala. In the present work, LTP of hippocampal commissural connections resulted in a decrease in N40 conditioning amplitude was observed. However, as was mentioned in the introductory section, commissural synapses are not likely to be carrying the auditory signal to the hippocampus. Rather, entorhinal cortex afferents are thought to be the primary input pathway for auditory information (Foster et al., 1988). Auditory signals may reach $\mathrm{CA} 3$ indirectly via the dentate gyrus, or via a direct projection (Yeckel and Berger, 1990; Colbert and Levy, 1992).

Onc mechanism by which commissural LTP could decrease the conditioning amplitude is by causing heterosynaptic depression of the perforant path synaptic response. Others have observed long-term synaptic depression in the perforant path (Pang et al., 1993) and negative heterosynaptic interactions between commissural and perforant path inputs in CA3 (Tomasulo and Ramirez, 1993). This is a prediction that can be tested in the future by looking for depression of the population spike evoked by perforant path stimulation following LTP of commissural fibers. Assuming that heterosynaptic depression of the perforant path is involved in depression of the conditioning (first tone) response, why does the amplitude of the test (second tone) response increase?

Previous work has shown that interneuronal excitation in the $500 \mathrm{msec}$ following the first tone correlates strongly with the diminished N40 response to the second tone (Miller and Freedman, in press). Current evidence suggests that the excitation of interneurons by the tone does not occur via feedforward activation by pyramidal cells (Miller and Freedman, in press). Rather, the excitation of interneurons by the tone must originate from an external source such as the perforant path. LTP of commissural input to interneurons could cause heterosynaptic depression of monosynaptic or disynaptic perforant path input to interneurons, which would diminish the interneuron response between the tones. This would result in an increased N40 response to the second tone. While most studies of heterosynaptic depression have been carried out in pyramidal cells (for a review, see Lin- 


\section{LTP OF 1. = HETEROSYNAPTIC DEPRESSION OF 2.}

\section{REVERSAL OF LTP 1. = REVERSAL OF DEPRESSION 2.}

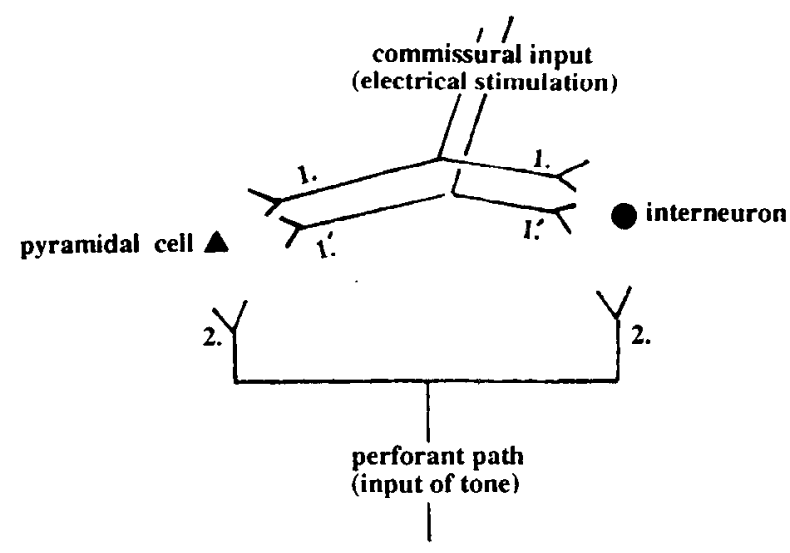

Figure 7. A schematic model of the synaptic contacts likely to be important to the effect of commissural LTP on auditory gating. Stimulation of commissural input 1 generates LTP at synapse 1 for both the pyramidal cell and the interneuron. The LTP also causes heterosynaptic depression of perforant path input to these neurons (2), resulting in the depression of N40 conditioning amplitude. The perforant path input refers to either the monosynaptic connection from the entorhinal cortex or the disynaptic connection via the dentate and the mossy fiber system. Heterosynaptic depression of the perforant path input to the interneuron prevents the inter-tone excitation of the interneuron that normally inhibits the pyramidal cell synaptic potential evoked by the second tone; thus, the N40 test potential increases and auditory gating is lost. The reciprocal connections between the pyramidal ccll and the interneuron are not shown. To reverse the auditory gating loss, a high-frequency stimulus is applied to commissural input 1 '. Reversal of the LTP at synapse 1 , without generating LTP at synapse 1', reverses the heterosynaptic depression of the perforant path inputs to the pyramidal cell and the interneuron. Auditory gating then returns to normal.

den, 1994), long-tcrm hetcrosynaptic depression has been demonstrated in GABAergic interneurons in the hippocampus (Reece and Redman, 1992), as well as in other brain regions (Kombian and Malenka, 1994). In addition, heterosynaptic depression of perforant path input to interneurons has been implicated in the response of the dentate to commissural tetanus (Tomasulo and Ramirez, 1993).

That synapses on different cell types may be involved in the changes in the conditioning versus test amplitudes is supported by a clear separation of the timing of the changes in some of the experiments (Table 3, Fig. 3B). The initial consequence of LTP induction was to increase test N40 amplitude while, in some cases, conditioning N40 amplitude remained unchanged (Fig. $3 B$ ). This transition is consistent with our hypothesized loss of interneuron activation by the perforant path and the resulting loss of inhibitory control of the test N40. Next, the conditioning amplitude decreased and the test amplitude decreased slightly also (although it did not return to baseline values). This transition fits well with a decreased perforant path input to pyramidal cells in response to both the first and second tones.

A possible model to explain the effect of commissural LTP, and its reversal, upon hippocampal auditory gating is shown in Figure 7. In other contexts, all of the interactions proposed in Figure 7 have been reported by others. From a condition of LTP at one synapse, it has not only been demonstrated that LTP at a heterosynaptic site (e.g., synapse 1') can introduce depression of the LTP at the first synapse (Levy and Steward, 1979; Christie and Abraham, 1992; Kerr and Abraham, 1993), but also that it is possible to induce depression of the LTP without getting LIP at the most recently tetanized synapse (Bradler and Barrionuevo, 1990). In addition, there is data demonstrating that depression at an unstimulated synapse (e.g., the perforant path) can be reversed if the LTP causing the heterosynaptic depression is reversed by tetanus of yet another heterosynaptic input (Bradler and Barrionuevo, 1990).

Although input from the entorhinal cortex may be necessary for the response of the hippocampus to tones, other facilitatory inputs are important as well (Harrison et al., 1988; Lunt-Leybman et al., 1993; Miller and Freedman, 1993). Heterosynaptic depression of another facilitatory input could have the same auditory gating effect as the perforant path depression proposed here.

Understanding the significance of the current findings in the context of a behaving animal depends upon the physiological relevance of LTP itself and whether or not long-term synaptic plasticity is related to information processing and/or learning and memory. In addition, although the effect of LTP upon auditory gating is not an artifact of high-frequency electrical stimulation, there may still be aspects of the stimulation protocol that are pertinent when assessing the physiological relevance of the results. The electrical stimulation is broad and nonspecific, characteristics which must certainly differ from the synaptic distribution of learning-induced changes. The hippocampus is extensively affected by the commissural LTP generated in this study, and therefore, the cells responding to the tone input and those experiencing LTP are likely to overlap. In a freely behaving animal, direct parallels with such an experimental outcome are likely occur only under a limited set of circumstances. Learning that is specifically related to the tone would, in all probability, affect the same cells involved in gating the response to the tone. Otherwise, situations in which cells involved in learning might fortuitously overlap with those involved in auditory gating would seem to be limited to conditions of information "overload" or involving hippocampal pathological conditions, such that only a small amount of hippocampal tissue would be available for processing functions.

If cells involved in auditory gating should experience auditory gating loss resulting from learning processes or from LTP of the commissural input, there are likely to be some measurable behavioral consequences in the behaving animal. As described earlier, a loss of auditory gating is correlated with the administration of psychotomimetic drugs in rats and with psychosis in humans, some of the symptoms of which are auditory in nature. However, it is not known how many different regions of the brain must experience the auditory gating loss to cause the auditory-specific features of psychosis. At least two other brain regions are known to exhibit auditory gating [the medial septum (Miller and Freedman, 1993) and the brainstem reticular formation (Bickford et al., 1993)]; it is probable that other extralemniscal auditory regions do as well. Here, we have attempted to specifically disrupt auditory processing in the hippocampus, and the behavioral sequelae are likely to be more limited than if gating in all of the extra-lemniscal systems was disrupted. Sakurai (1990) has proposed that the hippocampus is important for initiating motor response to sounds; if so, then loss of hippocampal auditory gating caused by commissural LTP might be expected to alter the motor response to repetitive sounds. Alternatively, the auditory gating disruption may interact with the place cell function of the hippocampus (O'Keefe and Nadel, 
1978; Breese et al., 1989; Wilson and McNaughton, 1993), making the spatial attribution of sound less rapid or accurate.

\section{References}

Adler LE, Pachtman E, Franks RD, Pecevich M, Waldo MC, Freedman $R$ (1982) Neurophysiological evidence for a defect in neuronal mechanisms involved in sensory gating in schizophrenia. Biol Psychiatry 17:639-654.

Adler LE, Rose G, Freedman R (1986) Neurophysiological studies of sensory gating in rats: effects of amphetamine, phencyclidine and haloperidol. Biol Psychiatry 21:787-798.

Andersen P, Bliss TVP, Skrede KK (1971) Unit analysis of hippocampal population spikes. Exp Brain Res 13:208-221.

Berger TW, Alger B, Thompson RF (1976) Neuronal substrate of classical conditioning in the hippocampus. Science 192:483-485.

Bickford P, Luntz-Leybman V, Freedman R (1993) Auditory sensory gating in the rat hippocampus: modulation by brainstem activity. Brain Res 607:33-38.

Bickford-Wimer PC, Nagamoto H, Johnson R, Adler LE, Egan M, Rose G, Freedman R (1990) Auditory sensory gating in hippocampal neurons: a model system in the rat. Biol Psychiatry 27:183-192.

Bradler JE, Barrioneuvo G (1990) Heterosynaptic correlates of longterm potentiation induction in hippocampal CA3 neurons. Neuroscience 35:265-271.

Brankack J, Buzsáki G (1986) Hippocampal responses evoked by tooth pulp and acoustic stimulation: depth profiles and effect of behavior. Brain Res 378:303-314.

Breese CR, Hampson RE, Deadwyler SA (1989) Hippocampal place cells: stereotypy and plasticity. J Neurosci 9:1098-1111.

Buzsaki G, Eidelberg E (1982) Direct afferent excitation and long-term potentiation of hippocampal interneurons. J Neurophysiol 48:597-607.

Christie BR, Abraham WC (1992) NMDA-dependent heterosynaptic long-term depression in the dentate gyrus of anaesthetized rats. Synapse 10:1-6.

Colbert CM, Levy WB (1992) Electrophysiological and pharmacological characterization of perforant path synapses in CAl: mediation by glutamate receptors. J Neurophysiol 68:1-8.

Collingridge GL, Kehl SJ, McLennan H (1983) Excitatory amino acids in synaptic transmission in the Schaffer collateral-commissural pathway of the rat hippocampus. J Physiol (Lond) 334:33-46.

Cooper JR, Friedman PJ (1958) The enzymatic oxidation of chloral hydrate to trichloroacetic acid. Biochem Pharmacol 1:76-82.

DeJonge M, Racine RJ (1985) The effects of repeated induction of long-term potentiation in the dentate gyrus. Brain Res 328:181-185.

Di S, Baumgartner C, Barth D (1990) Laminar analysis of extracellular field potentials in rat vibrissa/barrel cortex. J Neurophysiol 63:832840.

Douglas RJ (1972) Pavlovian conditioning and the brain. In: Inhibition and learning (Boakes RA, Halliday MS, eds). New York: Academic.

Edeline JM, Neuenschwander-El Massioui N, Dutrieux G (1990) Discriminative long-term retention of rapidly induced multiunit changes in the hippocampus, medial geniculate and auditory cortex. Behav Brain Res 39:145-155.

Eichenbaum H. Otto T (1993) LTP and memory: can we enhance the connection? Trends Neurosci 16:163-164.

Foster TC, Hampson RE, West MO, Deadwyler SA (1988) Control of sensory activation of granule cells in the fascia dentata by extrinsic afferents: septal and entorhinal inputs. J Neurosci 8:3869-3878.

Freedman R, Adler LE, Gerhardt GA, Waldo M, Baker N, Rose G, Drcbing C, Nagamoto H, Bickford-Wimer P, Franks R (1987) Neurobiological studies of sensory gating in schizophrenia. Schizophrenia Bull 13:669-677.

Harrison JB, Buchwald JS, Kaga K, Woolf NJ, Butcher LL (1988) 'Cat P300' disappears after septal lesions. Electroencephalogr Clin Neurophysiol 69:55-64.

Jirsa R, Poc P, Radil T (1992) Hippocampal auditory evoked response threshold in the rat: behavioral modulation. Brain Res Bull 28:149-153.

Keith VA, Mansbach RS, Geyer MA (1991) Failure of haloperidol to block the effects of phencyclidine and dizocilpine on prepulse inhibition of startle. Biol Psychiatry 30:557-566.

Kelly JP (1991) Hearing. In: Principles of neural science (Kandel ER, Schwartz JH, Jessell TM, eds). Amsterdam: Elsevier.

Kerr DS, Abraham WC (1993) A comparison of associative and nonassociative conditioning procedures in induction of LTD in CA1 of the hippocampus. Synapse 14:305-313.
Kombian SB, Malenka RC (1994) Simultaneous LTP of non-NMDAreceplor-mediated responses in the nucleus accumbens. Nature 368: 242-246.

Kubie JL, Ranck JB Jr (1983) Sensory-behavioral correlates in individual hippocampus neurons in three situations: space and context. In: Neurobiology of the hippocampus (Seifert W, ed), pp 433-447. New York: Academic.

Leung L (1979) Potentials evoked by alvear tract stimulation in hippocampal CA1 region of rats. 2. Spatial field analysis. J Neurophysiol 42:1571-1589.

Levy WB, Steward O (1979) Synapses as associative memory elements in the hippocampal formation. Brain Res 175:233-245.

Linden DJ (1994) Long-term synaptic depression in the mammalian brain. Neuron 12:457-472.

Luntz-Leybman V, Bickford PC, Freedman R (1993) Cholinergic gating of response to auditory stimuli in rat hippocampus. Brain Res 587:130-136.

McNaughton BL, Barnes CA, O'Keefe J (1983) The contributions of position, direction, and velocity to single unit activity in the hippocampus of freely-moving rats. Exp Brain Res 52:41-49.

Miller CL, Freedman R (1993) Medial septal neuron activity in relation to an auditory sensory gating paradigm. Neuroscience 55:373-380.

Miller CL, Freedman $\mathrm{R}$ (in press) The activity of hippocampal interneurons and pyramidal cells during the response of the hippocampus to repeated auditory stimuli. Neuroscience, in press.

Miller CL, Bickford PC, Luntz-Leybman V, Adler L, Gerhardt GA, Freedman R (1992) Phencyclidine and auditory sensory gating in the hippocampus of the rat. Neuropharmacology 31:1041-1048.

Miller CL, Hruby VJ, Matsunaga TO, Bickford PC (1993) Alpha-MSH and $\mathrm{MCH}$ are functional antagonists in a CNS auditory gating paradigm. Peptides 14:431-440.

Morris RGM (1990) Toward a representational hypothesis of the role of hippocampal synaptic plasticity in spatial and other forms of learning. Cold Spring Harbor Symp Quant Biol 55:161-173.

O'Keefe J, Nadel L (1978) The hippocampus as a cognitive map. Ox ford: Clarendon.

Pang K, Williams MJ, Olton DS (1993) Activation of the medial septal area attenuates LTP of the lateral perforant path and enhances heterosynaptic LTD of the medial perforant path in aged rats. Brain Res 632:150-160.

Racine RJ, Milgram NW, Hatner S (1983) Long-term potentiation phenomena in the rat limbic forebrain. Brain Res 260:217-231.

Reece LJ, Redman SJ (1992) Epsps in hippocampal interneurons exhibit long-term enhancement. Soc Neurosci Abstr 22:628.28.

Rogan M, Bordi F, LeDoux JE (1993) Long-term increases in auditoryevoked responses accompany tetanically-induced LTP in the thalamoamygdala pathway. Soc Neurosci Abstr 23:504.9.

Rose GM (1983) Physiological and behavioral characteristics of dentate granule cell In: Ncurobiology of the hippocampus (Seifert W, ed), pp 449-472. London: Academic.

Rose GM, Dunwiddie TV (1986) Induction of hippocampal long-term potentiation using physiologically patterned stimulation. Neurosci Lett 69:244-248.

Rose GM, Branch BJ, Humphreys AG, Moore CI, Diamond DM (1993) The population spike is a valid measure of hippocampal long-term potentiation. Soc Neurosci Abstr 23:375.16. Sakurai Y (1990) Hippocampal cells have behavioral correlates during the performance of an auditory working memory task in the rat. Behav Neurosci 104: 253-263.

Schlag J (1973) Generation of brain evoked potentials. In: Bioclectric recording techniques (Thompson RF, Patterson MM, eds), pp 272316. New York: Academic.

Solomon PR (1977) Rule of the hippocampus in blocking and conditioned inhibition of the rabbit's nictitating membrane response. $J$ Comp Physiol Psychol 91:407-417.

Squire L (1987) Memory and brain. Oxford: Oxford UP.

Stafekhina VS, Vinogradova OS (1975) Sensory characteristics of the cortical input to the hippocampus: the entorhinal cortex. $\mathrm{Zh}$ Vyssh Nerv Deiat 25:119-127.

Steward O, Tomasulo R, Levy WB (1990) Blockade of inhibition in a pathway with dual excitatory and inhibitory action unmasks a capability for LTP that is otherwise not expressed. Brain Res 516:292-300.

Swanson LW (1983) The hippocampus and the concept of the limbic system. In: Neurobiology of the hippocampus (Seifert W, ed), pp 319. London: Academic. 
Swanson LW (1992) Brain maps: structure of the rat brain. Amsterdam: Elsevicr.

Swanson LW, Teyler TJ, Thompson RF (1982) Hippocampal long-term potentiation: mechanisms and implications for memory. Neurosci Res Prog Bull 20:613-769.

Teyler TJ, Discenna P (1984) Long-term potentiation as a candidate mnemonic device. Brain Res Rev 7:15-28.

Tomasulo RA, Ramirez JJ (1993) Activity-mediated changes in feedforward inhibition in the dentate commissural pathway: relationship to epsp/spike dissociation in the perforant path. J Neurophysiol 69: 165-173.

Vayssettes-Courchay C, Sessler FM (1983) Evidence for sensory convergences in rat entorhinal cortex. C R Seances Acad Sci 3 296:877-879.
Voneida TJ, Vardaris RM, Fish SE, Reiheld CT (1981) The origin of the hippocampal commissure in the rat. Anat Rec 201:91-103.

Weinberger NM, Diamond DM (1987) Physiological plasticity in auditory cortex: rapid induction by learning. Prog Neurobiol 29:1-55.

Weinberger NM, Ashe JII, Metherate R, McKenna TM, Diamond DM, Bakin J (1990) Retuning auditory cortex by learning: a preliminary model of receptive field plasticity. Concepts Neurosci 1:91-132.

Wilson MA, McNaughton BL (1993) Dynamics of the hippocampal ensemble code for space. Science 261:1055-1058.

Yeckel MF, Berger TW (1990) Feedforward excitation of the hippocampus by afferents from the entorhinal cortex: redefinition of the role of the trisynaptic pathway. Proc Natl Acad Sci USA 87:5832-5836.

Zalutsky RA, Nicoll RA (1990) Comparison of two forms of long-term potentiation in single hippocampal neurons. Science 248:1619-1624. 